\title{
Response strategies for curriculum change in engineering
}

\author{
Anette Kolmos ${ }^{1} \cdot$ Roger G. Hadgraft ${ }^{1,2}$. \\ Jette Egelund Holgaard ${ }^{1}$
}

Accepted: 5 June 2015/Published online: 18 June 2015

(C) The Author(s) 2015. This article is published with open access at Springerlink.com

\begin{abstract}
During the last 25 years, there have been many calls for new engineering competencies and a corresponding gradual change in both curriculum and pedagogy in engineering education. This has been a global trend, in the US, Europe, Australia and now emerging in the rest of the world. Basically, there have been two main types of societal challenges that many engineering institutions have responded to: the employability skills of graduates and the need for a sustainability approach to engineering. These are two very different challenges and societal needs; however, the ways engineering institutions have responded form a consistent pattern across many of the content aspects. No matter the specific character of change, three very different curriculum strategies seem to have evolved: an add-on strategy, an integration strategy or a re-building strategy; the latter involves substantial curriculum re-design. The add-on strategy and integration strategy are the ones most commonly used, whereas the re-building strategy is at an emerging stage in most engineering education communities. Most engineering schools find it very challenging to re-build an entire curriculum, so smaller changes are generally preferred. The purpose of this article is to conceptualise these institutional response strategies in a wider literature and present examples of curriculum change within both employability and sustainability. We will maintain that all these strategies are based on management decisions as well as academic faculty decisions; however the implications for using the various strategies are very different in terms of system change, role of disciplines, leader interventions and faculty development strategies. Furthermore, institutions might use all types of response strategies in different programs and in different semesters. The conceptual framework presented here can provide analytical anchors, hopefully creating more awareness of the complexity of systemic change.
\end{abstract}

Anette Kolmos

ak@plan.aau.dk

1 Aalborg University, Vestre Havnepromenade 5, 9000 Aalborg, Denmark

2 Central Queensland University, Ooralea, QLD 4740, Australia 
Keywords Change strategies - Education for sustainable development ESD · Engineering education · Curriculum change $\cdot$ Employability $\cdot$ Sustainability · Complexity · Faculty development

\section{Introduction: employability and sustainability}

Several organisations have published reports calling for systemic change in engineering education with emphasis on employability, such as the learning of process skills, entrepreneurship and innovation (King 2008; National Academy of Engineering 2004; Nigel Spinks et al. 2006; Sheppard et al. 2008). At the policy level, this has been supported by governments emphasizing outcomes based education (OBE) and accreditation bodies have defined technical, process and professional skills as the central elements of the accreditation requirements, e.g. International Engineering Alliance (International Engineering Alliance 2013, 2015), American Board for Engineering and Technology (ABET) and European Accredited Engineer (EURACE) and Engineers Australia (Engineers Australia 2011) which indicates that there is a growing awareness of the need for integrated curricula that develop generic design and problem solving skills plus professional/business skills as well as disciplinary technical knowledge and skills.

In Europe, the Bologna process has required curricula with explicitly formulated learning outcomes in terms of knowledge, skills and competencies and especially entrepreneurship and innovation have been emphasized (Bologna Working Group 2005, p. 94; European Commission 2009). Most institutions in Europe-but also worldwidehave responded to these types of requirements by a series of different learning methodologies ranging from internships where students meet working life early on in education to implementation of projects that are carried out with companies (Graham 2010; Royal Academy of Engineering 2007).

In parallel to the employability agenda, there has been another change agenda going on within education for sustainable development (ESD), which in many countries is also run by political actors. At the academic level, it started out as a critical movement, which had roots back to the student movement of the 70s and the movement against nuclear power. During the $80 \mathrm{~s}$ it became clear that environmental issues were created by unlimited innovation and the growth of human consumption, which has caused issues for nature and for human health.

These critical political movements turned into official international policy, such as the Horizon 2020 programs in the EU (Brulin and Svensson 2012). UNESCO has been a pioneer in formulating the requirements within sustainability and has been running a UN decade of education for sustainable development with the overall goal to "integrate the values inherent in sustainable development into all aspects of learning to encourage changes in behaviours that allow for a more sustainable and just society for all" (United Nations 2014).

Today, some countries have formulated learning outcomes within sustainability like the Australian Stage 1 Competency Standard that includes sustainability (Engineers Australia 2011), the Swedish government (Swedish Higher Education Act), and the US ABET criteria 2011-2012. However, in most countries the learning of sustainability competencies depends on individual institutions (Johnston 2013).

A recent British study concludes that universities do have an impact on the environmental engagement in society and a change at a university level within this area is 
desirable; however, the university staff attitudes to integrate sustainability into the curriculum still have room for improvements (Cotton and Alcock 2012). A recent study from the Royal Institute of Technology, Sweden, indicates that sustainability is regarded among the lowest ranked priorities of a number of engineering competencies (Magnell et al. 2014).

Similar results are found by (Shephard and Furnari 2012) pointing out four different viewpoints among academic staff on education for sustainability of which only one viewpoint is in favor of integrating these elements into curriculum, and the resistance among academic staff is an issue in this matter. In general, academic staff might not be against sustainability; however, arguments such as academic freedom, the need to teach disciplinary skills and critical thinking skills are more highly valued (Shephard and Furnari 2012). Other studies indicate that the pressure for change has to come from the students more than faculty (Broadbent et al. 2010; Haase 2013a, b).

The employability and sustainability agendas focus on different aspects of curriculum development. The employability agenda is mostly skills and competence oriented whereas the sustainability agenda has been a mix between knowledge and societal values on the one side and skills and competencies on the other side (Clark et al. 2001; Tryggvason and Apelian 2011).

Common to both employability and sustainability is that the engineering curricula at many places have included elements of both, to varying degrees; however, to expand their prominence in the curriculum, we believe that a process oriented approach to the remaking of a curriculum is required, involving external stakeholders (Knight 2001). This applies sound systems engineering principles to the engineering curriculum itself. There are tensions between these two agendas as they do not point in the same direction, but the way institutions have responded share similarities because both require curriculum change.

As the above developments indicate, there have been some changes in engineering education-and there has been resistance from some academic faculty. Change in engineering education is a slow process, and making change is an emerging research area (Gibbs 2013).

The existing change pattern is that individual faculty (early adopters) carry out changes and that change typically occurs within single and isolated courses (subjects/units); however, it is very seldom a systemic change. Graham (2012) identifies four common features of successful systemic change in engineering education: firstly it has been triggered by external reasons (often a crisis of enrolments or accreditation), secondly an interconnected curriculum where academics see meaning and positive impact on the students is desired, thirdly academics are continuously involved in improvement of curriculum change and evidence of results is provided, and fourthly a participatory vision of developing a world class education is put in place.

Meeting all these characteristics will involve a comprehensive institutional and academic involvement. However, change is seldom based on such a comprehensive approach but much more based on small steps in the classroom (Louvel 2013). Even for the classroom level, resistance is an issue and not much change has happened (Schierenbeck 2013), although a recent study on faculty attitudes indicates that faculty are more positive towards individual change strategies rather than system and strategic change (BesterfieldSacre et al. 2014).

Change at the individual unit level is important but there is a missing link between the individual change and the organisation. Graham points out that the individual level has to interact with the organisational (program) level and there is a need for developing models for change that incorporate both levels in new ways (Graham 2012). 


\section{Making change}

The Journal of Engineering Education has recently published an issue on systemic change (Vol. 103, No. 2, April 2014), which has contributed many interesting perspectives. JEE received 53 proposals for articles; however, only seven were invited for publication, as most of the articles described change in single courses (McKenna et al. 2014). These isolated cases of changes in courses represent an important stage for seeking a more general model, but it illustrates that the research in this area is more empirical and case based and has hardly been conceptualised into more theoretical and model driven approaches.

Henderson et al. (2011) is one of the core references, in all articles except two, and forms the theoretical framework for the analysis of the work in several of the articles (Henderson et al. 2011). These authors have reviewed the literature on "how to promote change in instructional practices used in undergraduate science, technology, and mathematics (STEM) courses". They propose four categories of change: (1) disseminating: curriculum and pedagogy, (2) developing: reflective teachers, (3) enacting: policy, and (4) developing: shared vision (Fig. 1).

These four categories represent a grid of educational change in two dimensions: (1) individuals versus environments and structures and (2) intended outcomes: prescribed or emergent. This represents the current stage of the research in STEM, however it does not represent a coherent model of integrative systemic change.

The study also clearly shows that different communities of researchers and educational developers focus on different dimensions, such as faculty development researchers focusing on reflective teachers, STEM researchers focusing on curriculum and pedagogy, and higher education researchers with a primary focus on policy. Consequently, the research among faculty developers and STEM researchers focuses primarily at the individual level while higher education researchers focus on environments and structures.

However, there is an issue that the different communities seldom work together and, thus, more coherent systemic change in engineering education is hard to enact. Development of a shared vision at the School, Faculty or University level is hardly ever attempted. When attempted, it is seen as a 'box ticking' exercise with little sense of commitment other than to have a bland statement on the website. Rarely do such visions become the driver for

Fig. 1 Overview and conceptual underpinnings of the four categories of change strategies. Acronyms in the figure: SER disciplinary-based STEM education researchers, FDR faculty development researchers, $H E R$ higher education researchers) (Henderson et al. 2011)

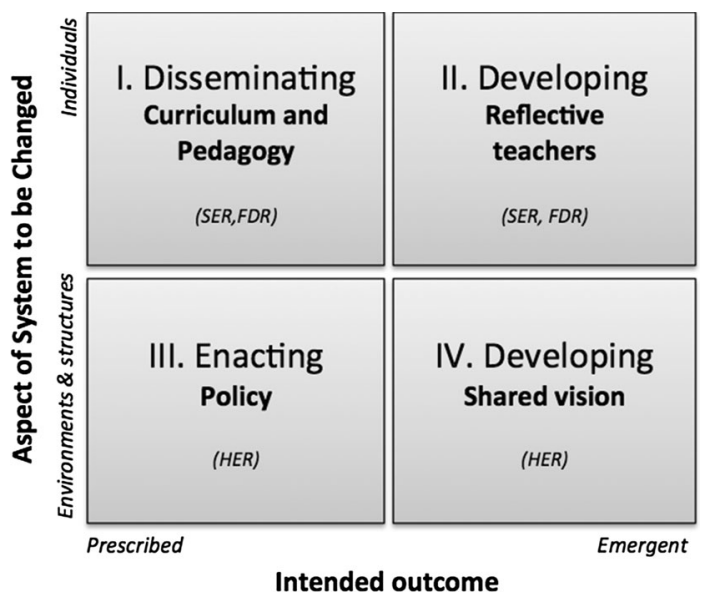


widespread change of the organisation and of the curriculum (Goldberg and Sommerville 2014).

Furthermore, this model is used for characterising core change strategies; however, in the literature, the four strategies are not described as scalable or as interacting in a whole of system approach. Systemic change relies on change at the individual level as well as the organisational level and the two levels should interact, as organisations are open systems that rely on individuals' capabilities. There is a need for modelling this interaction at a systemic level and sharing experiences for where it does exist.

\section{Three models for change: combining what and how}

Very few models of systemic change have been reported in the literature. For a model of systemic change, the combination of the what (in which directions are we going), and the how (how to implement the changes) are important elements (de Graaff and Kolmos 2006; Kolmos and Graaff 2014).

In the education for sustainable development (ESD) and the engineering education for sustainable development (EESD) literature, Sterling (2001) is one of the champions who is often referenced. He has developed three types of educational responses to sustainability that point in three different directions for developing universities: Education about sustainability, Education for sustainability and Education as sustainability. The three types of response strategies represent points on a systemic scale.

1. Education about sustainability is an assimilation strategy where sustainability subjects are included in the formal curriculum. There is no change of educational paradigm. This is an add-on strategy.

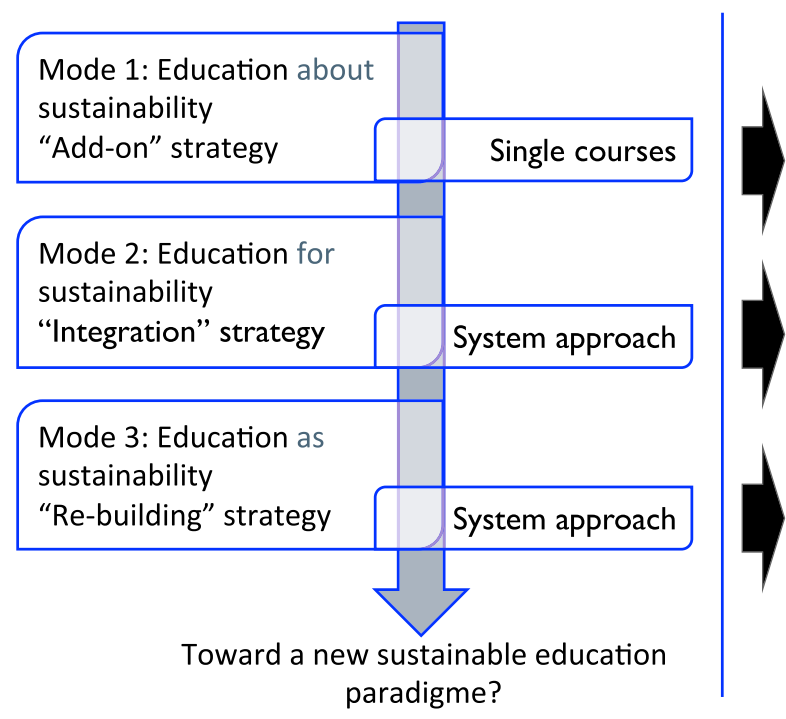

Linear block system and awareness

Critical reflection Collaboration with companies

Building a "new education" Values, identity, commitment, risks, contextualising and collaboration with companies and society

( Adapted from Sterling 2001)

Fig. 2 Three curriculum response strategies 
2. Education for sustainability includes content and values, and will involve some modifications of the program, but the educational paradigm remains intact. This leads to an integration strategy.

3. Education as sustainability is a transformative, epistemic learning response and will involve an educational paradigm shift involving the whole learning person and the entire institution (or at least a whole Faculty or School). This requires a re-build strategy for the curriculum and for the organisation.

Holgaard et al. (2010) have combined Sterling's three modes that mainly focus on the content (the what) with strategies for how to change curriculum (Fig. 2).

The add-on strategy is basically a component strategy that adds or modifies components without disturbing the existing structure. An example would be to bring sustainability into the curriculum by adding a new course, such as a new sustainability elective or a first year project that includes sustainability.

For both the employability and the sustainability agenda, an add-on strategy involves adding new courses or learning activities within existing courses, or it might be organized as co-curricular activities, such as the Engineers Without Borders Challenge, used in Australia, NZ and the UK (Engineers Without Borders 2014).

The add-on strategy is in line with the basic philosophy of academic freedom within the university (Barnett 2010). It has the advantage that individual academics, as early adopters, can begin to lead change within their school or department. Without doubt this is the most widespread strategy for curriculum change and it is often seen as an individual strategy. But even if one single academic faculty member (or a small teaching team) can carry these change activities, the strategy is part of a system strategy-the university system facilitates such changes.

The integration strategy goes one step further by mapping and coordinating the various courses and integrating employability aspects such as project management skills, entrepreneurship or even life-cycle analysis. Change to the curriculum structure may be limited, but change at the individual subject level can be significant; the degree of coordination and curriculum overview required increases significantly and such change usually requires the support of the academic managers, e.g. program leaders, Deans and Heads of School. Many accreditation precincts now expect at least this level of whole-of-program integration, which must be demonstrated through curriculum mapping of outcomes versus courses (units) (Engineers Australia 2011).

The re-building strategy corresponds to emerging university types like the ecological university (Barnett 2010). This is a fundamental change of academic view linking academia with societal context and needs. It goes further than the second modes formulated by Sterling and Jamison (Jamison et al. 2011; Sterling 2001) by emphasizing a shared set of values, identity and commitment. It is about educating engineers who will become change agents after graduation, with an understanding of stakeholder needs and the wider societal impact of engineered systems within the innovation process.

Such change will require strong institutional support, often from the highest level of the university. One difficulty is that universities struggle to articulate a vision of their students as 'change agents' driven by values. An exception would be The Franklin W. Olin College of Engineering (2015).

Sterling's three modes also correspond to the three modes developed by Jamison et al. (2014): the academic mode, the market-driven mode and the hybrid learning mode (Jamison et al. 2011, 2014). 
The academic mode represents the traditional university with an emphasis on theory and scholastic training including a tolerance for an add-on strategy to curriculum development.

The market-driven mode covers the technological innovation, entrepreneurship and collaboration with companies, emphasizing the employability agenda with focus on outcomes, skills and competencies, especially entrepreneurship and innovation.

The third mode - the hybrid learning-is focused on societal values and change including transformative learning. Several authors and theories thus point at common understandings of the directions for change and Sterling's great contribution is that he is linking both the "what", the "how" and the "why" in the change process by creating an inner logic.

Therefore, the organisation of the learning process should complement the content of students' learning. Education as sustainability will require both knowledge, skills and a higher emphasis on the development of each student's identity (Barnett et al. 2001).

\section{Levels in systemic change}

In the literature on problem based and project based learning (PBL), several authors focus on systemic change as PBL implies a fundamental change of teaching and learning practice. No matter if the focus is on problem-based learning, (Barrows and Tamblyn 1980; Felletti and Boud 1997; Savin-Baden 2003), project-based learning (Edström and Kolmos 2014), or merging PBL models (Kolmos and Graaff 2014), the degree of implementation of PBL will depend on the degree of systemic commitment and involvement in the change process.

Fullan presents a systemic approach emphasizing that the outcome of an educational change process is not only a change in student learning, but a change also in organizational capacity (Fullan 2007a). The persistent factor is faculty and organisational policies and practices, as students will graduate (Boyce 2003). Furthermore, he emphasises that change is a continuous process, and not an event (Fullan 2007b), which reinforces the need for reflective teachers and reflective academic managers (Fig. 1).

Change processes will take time and need regular energizers and an organisational approach, together with an educational approach. Within the framework of Fullan (2007a), de Graaff and Kolmos (2006) present a model for systemic change with four elements: (1) identify the core elements in the curriculum that have to undergo change and should be aligned, (2) identify the organisation and culture of the teaching unit, to address the structural level, (3) identify values and conceptual change with a focus on the individual level, and (4) identify physical spaces and resources. All elements are necessary to include in a systemic change process (de Graaff and Kolmos 2006).

Kotter is often referred to as one of the core systemic theorists in the field (de Graaff and Kolmos 2006; Kotter 1995; Reidsema et al. 2013). Kotter emphasises that there are two elements that are often overlooked in the change literature, namely the participants' sense of urgency and the creation of common vision and recent research presents results that shared vision is one of the lowest priorities among US faculties, although the shared vision supports the discussion of the what-in which directions engineering education should aim (Besterfield-Sacre et al. 2014).

A change journey also includes discussion of the values and intentions that are shared by the academic community. Vision development should be seen as a staff development exercise. Two recent projects in Australia developing a shared understanding of 
engineering curricula support this view (Baillie et al. 2012). The value is in the rich conversations that are generated using an appropriate methodology. Visions are connected to values, beliefs and attitudes and can be as important as the structural changes.

To sum up the elements of change required at an institution, there are two main levels that should be addressed—both the organisational and the individual level—and change of a curriculum interacts with change in attitudes and beliefs, see Table 1 . In between the individual level and the organisation level, there are intermediate levels, which can be a discipline within a program, e.g. structural engineering as part of civil engineering. It might be easier to get academics to rethink a few courses/subjects than the entire program. This gives them confidence to then operate at the bigger scale.

However, there are two dimensions that need to be addressed: both the curriculum and the culture. Leadership of change needs to make transformation happen from the individual to the organisational level with a focus on both the curriculum as well as the culture (Marshall 2007).

\section{Leading systemic change}

Involving both individual and organisation levels requires leadership. (de Graaff and Kolmos 2006) highlight that systemic change involves both top-down and bottom-up processes, and that faculty and management should be involved in a constant conversation and debate and co-creation of visions and strategies. All levels in the organisation should be involved and change agents in terms of leaders, academics and faculty developers are needed in all phases from the initial phase to the sustaining phases of change. These same practices of co-creating learning visions should be similarly implemented in the classroom to engage students in their personal learning quest.

This more complex approach is supported by (Brulin and Svensson 2012) describing two strategies for curriculum change: (1) a planning-steered (top-down) development model that is result-oriented and a one-way communication plan for managers, and (2) development-supportive strategy that is much more process oriented and dialogue based. The ownership of the change process is one of the key factors in change and this might happen in comprehensive and common change processes.

Hannah and Lester (2009) define leader interventions at three levels for systemic change in learning organisations: micro level corresponding to the add-on strategy, the meso level corresponding to the integration strategy and the macro level more in alignment with the re-building strategy (Hannah and Lester 2009) (Fig. 3).

Table 1 Levels of change

\begin{tabular}{lll}
\hline Level of change & Curriculum & Culture \\
\hline $\begin{array}{c}\text { Organisational level } \\
\text { (re-building) }\end{array}$ & $\begin{array}{c}\text { Coordination and } \\
\text { organisation of } \\
\text { curriculum }\end{array}$ & $\begin{array}{c}\text { Vision and reflections on practice as element in a } \\
\text { cultural and collective conceptual change }\end{array}$ \\
$\begin{array}{c}\text { Intermediate levels } \\
\text { (integration) }\end{array}$ & $\begin{array}{c}\text { Smaller parts of } \\
\text { curriculum }\end{array}$ & Sharing of ideas \\
$\begin{array}{c}\text { Individual level } \\
\text { (add-on) }\end{array}$ & $\begin{array}{c}\text { Single courses } \\
\text { Individual beliefs and conceptual change }\end{array}$ \\
\hline
\end{tabular}




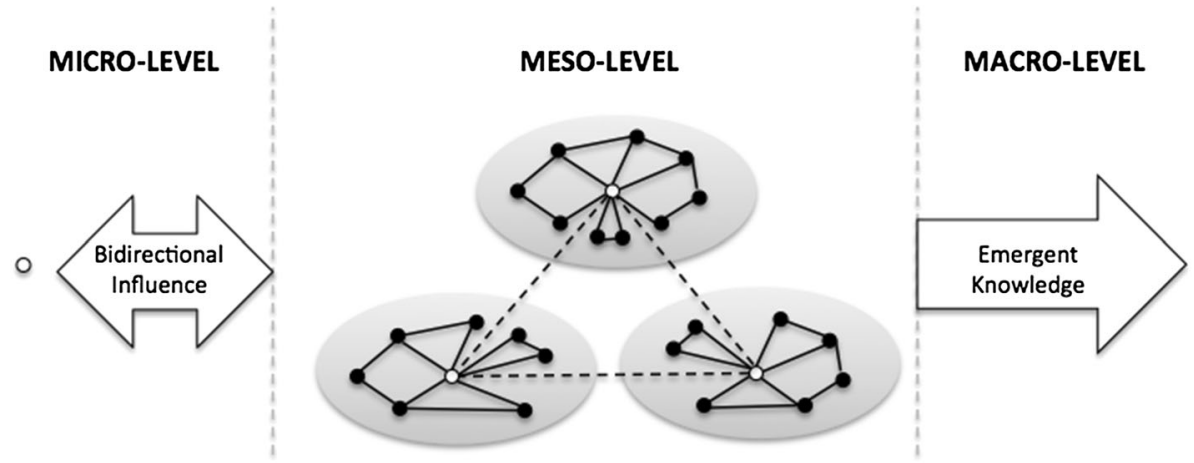

Fig. 3 Model of individual, network and systems level leader interventions. Modified version (Hannah and Lester 2009)

In an organisational change, all three levels are important. The micro-level represents the individual readiness and the conditions for any organisational change. It encourages and develops early adopters who then have the skills to take leadership roles as change agents at the integrative meso-level. The meso-level consists of several knowledge network clusters by which each of the clusters have catalysts who can reach out to other clusters, and the macro level refers to institution, society and global networks.

Their point is that for knowledge organisations, there is a need for leader interventions at all levels for knowledge organisations to develop. In this model, the levels interact-and the micro-level acts as an individual capacity building process for participating in the meso-level. The meso-level focuses on creating communities and knowledge catalysts that can work within and across networks, leading to an emergent stage in the organisation.

The meso-level can be a coherent discipline with responsibility for a part of a program, for instance. This discipline can reorganise its teaching focus more easily than the entire program can be changed. This builds confidence in making larger changes to an entire program (Seidel et al. 1994).

The meso level is strategically important in a system change by building up networks or communities of practice. It could be networks of academics within disciplines, with the profession outside the university, and with society more broadly. These networks exist in many places already, but the model indicates that the coordination among networks at an organisational level is important.

Furthermore, the transformations from the micro/individual level to the meso/departmental level and further on to the macro/organisational level need leader interventions addressing different types of activities with different purposes. Leadership in higher education and, in particular in engineering education, might be an overlooked area. As for teaching, the same attitude is widely spread in the academic culture, that leadership and management is something that academics just do. With the new management culture in universities, there has been a tendency that leadership has become a career path focused on command and control, but still the main qualifications for the jobs are academic merits.

Leader interventions should be directed to create (a) common visions and ideas for directing the developments and change, (b) organisational consensus, (c) relevant skills and competencies to carry out the change, (d) organisational incentives to keep academic staff motivation, (e) resources for the extra work in curriculum change and finally, (f) an action 
plan for the whole organisation (Knoster et al. 2000). Along with a series of leader interventions, leaders also need to develop their leadership capabilities (Drew 2010).

\section{Faculty development as leader intervention}

In most Scandinavian countries, faculty development is compulsory by national law; in other countries, the requirement for compulsory faculty development is based on institutional priorities. During the last 20 years, faculty development at university level has manifested itself as an acknowledged need at many universities, which has often empowered faculty to participate in and to lead change.

The roles of faculty developers are diverse, but they have often been seen as the change agents at universities. The role of an institutional change agent might have evolved further into a collaborative partnership with faculty and this involves a constant negotiation with academic staff (Debowski 2014).

However, the academic faculty training centres can also be seen as a leader intervention at the functional level. Although these academic training centres must develop their relationship to the management level to define their own roles, they usually also build a strong and independent research and development profile. The role of faculty development

Table 2 How to develop a university's teaching and learning. Modified from Gibbs (2013)

1 Developing individual teachers
a. Practices
b. Thinking
c. Motivation
d. Ability to "self-improve" so that they need little or no support in the future

2 Developing groups of teachers through
a. Communities of practice
b. Leadership of teaching

3 Developing learning environments

4 Developing the institution through

a. Change inflexible teaching room booking system

b. Facilities that support teaching

c. Educational policies

d. An institutional learning and teaching strategy

e. Aligning components within the learning and teaching strategy

f. An institutional pedagogy

5 Influencing the external environment

6 Identifying emergent change and spreading "best practice"

7 Developing students

8 Developing quality assurance systems

9 Developing the credibility of teaching improvements effort

10 Undertaking educational evaluation

11 Undertaken educational research, or educational development research, and supporting the scholarship of teaching across the institution 
units can be quite complicated as the mediator of development and change can be caught between the leaders and the faculty. There can be conflicts with the leaders and a shared vision of the future of higher education is often missing, with faculty development units spending most of their time dealing with poor teaching quality rather than shaping the learning agenda for the next 10 years.

Graham Gibbs is one of the pioneers of faculty development in the UK and is well known internationally as one of the founders of the International Consortium for Educational Developers (ICED). In a recent article, he outlined 11 different faculty development activities ranging from developing the individual teacher to developing the institution and quality development systems (Table 2) (Gibbs 2013).

Gibbs (2013) reports on changing paradigms for teaching and learning as faculty development has moved from a focus on the individual classroom to a broader focus on learning environments, or building communities of practices within an institution or department. Organisational change has become an important part of educational change involving sustained change in the long run (Boyce 2003; Drew 2010). Changing curriculum and changing university organisations is a continuous process of negotiation, facilitated by leaders within the university.

Relating Gibbs (2013) to the model by Hannah and Lester (2009), there seems to be a trend to focus more on the meso or the institutional level; however it seems not to be present in the literature. Within engineering education, the success of the CDIO initiative (conceive, design, implement and operate) which started out in 2004 and now has more than 110 members from all over the world (CDIO 2014a) underpins the point that there is a trend in moving to a more combined systems approach.

The CDIO approach emphasises an institutional approach, including curriculum coordination, integration of process and professional, quality development and faculty development. CDIO is an important actor on the international scene to assist systemic change in engineering education.

Table 3 Summing up the conceptual framework for three systemic response strategies for curriculum change

\begin{tabular}{|c|c|c|c|}
\hline & Add-on strategy & Integration strategy & Re-building strategy \\
\hline Curriculum & $\begin{array}{l}\text { Small changes to existing } \\
\text { curriculum structure, e.g. } \\
\text { new electives }\end{array}$ & $\begin{array}{l}\text { Competence integration in } \\
\text { existing courses and high } \\
\text { degree of coordination }\end{array}$ & $\begin{array}{l}\text { Crossing or merging } \\
\text { disciplines with a high } \\
\text { degree of coordination } \\
\text { and management }\end{array}$ \\
\hline $\begin{array}{l}\text { Levels of } \\
\text { systemic } \\
\text { change }\end{array}$ & $\begin{array}{l}\text { Systemic maintenance and } \\
\text { optimization }\end{array}$ & $\begin{array}{l}\text { Academic negotiation and } \\
\text { collaborative curriculum } \\
\text { coordination with system } \\
\text { support }\end{array}$ & $\begin{array}{l}\text { Academic shared vision } \\
\text { and system change }\end{array}$ \\
\hline $\begin{array}{l}\text { Leading } \\
\text { systemic } \\
\text { change }\end{array}$ & $\begin{array}{l}\text { Micro: preserver and } \\
\text { response to external } \\
\text { requirements. Bottom up } \\
\text { and academic freedom }\end{array}$ & $\begin{array}{l}\text { Meso: strategic coordinator } \\
\text { and motivator. Both top } \\
\text { and bottom up }\end{array}$ & $\begin{array}{l}\text { Macro: vision, motivator } \\
\text { and change agent. Both } \\
\text { top down and bottom up }\end{array}$ \\
\hline $\begin{array}{l}\text { Faculty } \\
\text { development } \\
\text { strategy }\end{array}$ & $\begin{array}{l}\text { Focus on the individual } \\
\text { academic staff level }\end{array}$ & $\begin{array}{l}\text { Focus on the individual and } \\
\text { institutional level within } \\
\text { disciplines }\end{array}$ & $\begin{array}{l}\text { Focus on the individual, } \\
\text { institutional level beyond } \\
\text { existing disciplines }\end{array}$ \\
\hline
\end{tabular}




\section{Three systemic change strategies}

In previous section various aspects of systemic change have been addressed, first defining the "what" as the add-on, integration and the re-building curriculum strategies, followed by the "how" components in a change process such as organisational levels, levels for leadership, and faculty development. Each of these components has different functions in the three curriculum strategies which is summarised in Table 3.

Perhaps change start with an add-on strategy, leading through integration to a rebuilding phase. Not all faculties manage to get to the re-building phase. Cultural change at the individual and organisational levels must be addressed to reshape curriculum at this whole-of-system level. The remainder of the paper provides examples of how change can be effected.

\section{Exemplifying the add-on strategy}

Reviewing the literature in the area of sustainability reveals mostly "the best practice perspective" (Fadeeva et al. 2010; Holmberg et al. 2012; Johnston 2013; Jones et al. 2010). The examples come from universities all over the world, but in particular from Australia, Europe and the US. Many of the best practice examples come from standalone courses that have been added into the curriculum, which is the most common strategy within engineering education (Sheppard et al. 2008).

There are many different versions of the add-on strategy. At many European universities, many new centres have been established to meet requirements for the employability agenda, both process skills and entrepreneurship, including examples from Germany where centers for transferable skills have been established. Students get credits when passing the courses-but mostly as elective courses.

In the US, co-curricular activities are common. Co-curricular activities are study activities outside the curriculum to develop students' academic and non-academic skills. These activities include service-learning projects as well as large cross-disciplinary projects such as the Formula SAE competition or micro-satellite projects.

An interesting example is the National Academy for Engineering Grand Challenges Scholars Program. It was initiated by the National Academy for Engineering (NAE), which is external to universities, and universities apply for participation. The NAE Grand Challenges Program is an attempt to bring sustainability into US programs and there are many US institutions that have signed up for the program. This strategy is an exemplary strategy for creating an external and prestigious network pressure on the existing curriculum.

As an add-on strategy, co-curricular activities are rare in many European countries as such activities normally are implemented in the formal curriculum. However, it is a strategy for building up components that can be integrated in the curriculum later on, unless it is seen as an advantage to run co-curricular activities.

The most typical add-on strategy is the development of new courses in the formal curriculum. One successful example is the Engineers Without Borders (EWB) Challenge, originally adopted at most universities in Australia and now with participating universities in New Zealand and the UK (Crosthwaite and Kavanagh 2010; Engineers Without Borders 2014). The Challenge is usually integrated into a first year course that introduces students to professional practice by placing them into a small team to research a life improvement strategy for a village somewhere in the developing world (Nepal in 2014). Typical 
improvements focus in areas such as water supply, sanitation and health, food production, housing, energy supply, transport, communication, education, etc. The focus is on sustainable solutions, with students needing to justify their solutions using social, environmental, economic and technical criteria. Through this project, students explore the role of engineering in society, ethics, team skills, project management, communication, both written and oral, information skills (library search plus collation and review of sources), critical thinking and creative thinking, e.g. (RMIT 2014).

The add-on strategy is normally regarded as a single course strategy aligned with the academic university. Research is a main driver for curriculum change together with external requirements such as accreditation. As such, the add-on strategy is a response strategy at the system level to the perceived societal requirements for new competencies and knowledge, as reflected in accreditation criteria (Holmberg et al. 2012; International Engineering Alliance 2013).

The role of the leader or manager will mainly be to make sure that the curriculum system responds to these external requirements such as new competencies assessed by quality assurance systems, and to regulate and maintain the existing system. The disciplines remain mainly untouched within the course structure of the curriculum.

There is faculty development-however, mainly focused on training of the individual faculty member to develop their teaching and learning methods and skills, mostly with the goals of making reflective teachers. Active learning or even project based learning might be integrated in the existing courses.

The advantage for academic faculty is that they can make change on their own and might only have to negotiate with possible co-teachers. This makes the change process limited to single courses; however it might also be a launch pad for a more comprehensive change (the integration strategy). The disadvantage is that the change is dependent on the individual faculty and if that person leaves, the new teaching and learning practice may vanish as well.

\section{Exemplifying the integration strategy}

In the literature, there are examples of how sustainability can be implemented at a more systemic level and also integrated at an institutional level, although this should be expected due to national policy requirements e.g. in Sweden and Australia. Many of the examples are a joint implementation of employability skills and sustainability and it is very rare that sustainability content has dominated the change by itself (Crawley et al. 2014).

At the international level, the CDIO community is probably the largest community carrying out this philosophy. The vision of CDIO is to develop engineering education based on fundamentals, but with a comprehensive and interconnected curriculum, using design based learning processes, integration of professional skills, and active learning. The CDIO standards emphasize overview and interaction in the entire curriculum as well as in the single discipline.

The CDIO initiative has formulated a long list of standards and criteria which basically covers a coordinated and comprehensive curriculum development practice (CDIO 2014b). Integration of employability skills into the disciplines is one of the core criteria for the CDIO society, together with more student projects. Implementations range from small changes in single courses (add-on) to more comprehensive change across many courses, e.g. a specialisation sequence (integration).

One example illustrating the integrated strategy within sustainability is from Chalmers University. The strategy for implementing sustainability in the courses was based on three 
strategic elements (working with faculty): (1) creating a neutral ground which was a platform for sharing ideas and having overview of the organisation, (2) build on individual engagement and commitment which is aligned with a bottom-up strategy and (3) communicating a clear strategy from the management. At the curriculum level, there are compulsory courses that the students have to participate in; however, in many programs, sustainability has been integrated in existing courses, as e.g. in mechanical engineering. The result is that sustainability today is an explicit part of the curriculum (Holmberg et al. 2012).

Another example is a civil engineering curriculum that was refocused around the issue of sustainable infrastructure, after consultation with industry partners (Hadgraft et al. 2004). Similar changes were also conducted within the chemical engineering program at the Royal Melbourne Institute of Technology (RMIT University) in Melbourne, Australia (Hadgraft and Muir 2003).

A series of industry meetings was held with a range of engineering employers and graduates to seek their input into the new program and the following capabilities were identified and integrated into the curriculum:

- Sustainability Balance the technical, economic, environmental and social demands of a problem; protect safety, health, and welfare.

- Problem solving and decision-making Model engineering problems using a systems approach and appropriate assumptions; use a range of decision making (evaluation) methodologies; identify the criteria to be used in decision making (e.g. sustainability); use a range of engineering analysis tools and software; access information from a wide variety of sources, discern their value and use; design and conduct experiments

- Technical competence (engineering analysis) conceptualise, plan, design, construct and manage civil infrastructure systems; analyse and interpret field and laboratory data

- Teamwork and leadership Operate within an engineering organisation; manage projects and contracts; develop quality plans; provide constructive feedback to team members; resolve conflict in a team; lead a team; work with other disciplines in a team with conflicting needs

- Communication Communicate effectively listen, observe, speak, draw and write; communicate results qualitatively, quantitatively, graphically, electronically, textually; communicate processes of thinking and reflection (including giving constructive feedback)

- Personal development Be conscious of their own values; adhere to professional ethics; plan their career; reflect on experience; improve their own future practice; engage in lifelong learning

The learning and curriculum change is that engineers should become more employable and be able to apply their knowledge to practical and relevant problems from the engineering workplace. So this is basically a trend where students have to develop skills and competencies and apply their knowledge to real life problems (Cameron and Hadgraft 2010).

The integration strategy requires coordination and mapping of learning outcomes in smaller part of the curriculum and the various disciplines, but it does not necessarily involve a merge of disciplines or courses. Multidisciplinary projects are rare.

Change at the program level also involves an overview and assurance of overall learning outcomes, with coherence between the elements and progression and coordination among the various disciplines, plus integration of new requirements such as employability and sustainability skills. This will be a challenging process at the system level, and it will require leader intervention to map existing courses, negotiate with academic staff to 
motivate them towards more coordinated actions in further integrated curriculum development. If diverse courses are to be developed, with integrated learning outcomes such as employability skills, it will require training of faculty and collaboration and negotiation with other colleagues.

Compared to the add-on strategy, the role of academic managers and the faculty development unit is much more far-reaching at an institutional level. The successful intervention will be the creation of strong network clusters or communities of practice.

The advantage with this strategy is that the system will get involved and there will be an obvious need for curriculum coordination. However, the change in single courses might affect integration of some extra learning outcomes, but might not leave space/room for more complex student learning processes (and projects). The courses will basically still have their own lives and will be run by individual course holders or disciplinary teams.

However, the disadvantage is that the system will still be dependent on the single staff initiative and vulnerable because, if the single academic leaves, the change in the course might disappear. Even if there is a system approach to the integrative strategy, it does not mean that the system will control it the entire time. The mapping of learning outcomes in the courses and creation of progression might happen several times; however, the focus of the courses will exist inside the courses more than across courses, unless leader interventions have managed to create a very strong network structure to renew and facilitate the system.

\section{Exemplifying the re-building strategy}

Sustainability as a concept has an underlying societal value orientation, as it is the interaction and integration of environmental, economic and social considerations. There is an ongoing research conversation on combining the learning of sustainability with social learning, addressing the need for more complex and interdisciplinary knowledge and learning and as an element in facilitating emergence in the field (Wals 2007; Wals and Corcoran 2012). Likewise, there are contributions from systems thinking and also, from a Science, Technology and Society (STS) perspective, to stress the need for developing an interdisciplinary understanding of sustainability and the context it will work within (Baillie et al. 2012).

The re-building strategy corresponds to the emerging university types like the ecological university (Barnett 2010) or hybrid learning (Jamison et al. 2014). It is a fundamental change of academic values linking academia with societal context and needs. It goes beyond the integration strategy by emphasizing values, identity and commitment as a central part of the academic approach. Academic knowledge is also regarded as a much broader concept, combining disciplines and social context. Engineers in this respect are regarded as change agents who need an understanding of the societal impact and needs within the innovation process.

One of the difficulties of such an approach is that universities (academics) are uncomfortable discussing or proposing values. Whose values matter? One set of authors who have made progress in this direction is (Baillie et al. 2012) who propose the idea of a heterotopia, a place or space where new conversations can be had, including the liminal, 'a space of uncertainty and flux'. In these spaces of not-knowing, conversations can be had that seek answers to what the stakeholders value rather than seeking to impose our own values on the stakeholders.

This is a focus on understanding problems rather than imposing traditional solutions. For example, understand the needs for transport before building expensive transport 
infrastructure. Perhaps the infrastructure can be avoided completely by reshaping or removing the transport needs? Videoconferencing is increasingly replacing air travel to business meetings, for instance.

Another issue is that it will involve a new understanding of the role of the university, including the collaborative aspect with the surrounding society, and a new understanding of teaching and learning in the curriculum supporting structures that are self-renewing.

Student centred curricula based on projects are process-oriented rather than productoriented; the curricula are adapted over time without the need for Academic Board approval. Academics are immersed in the process of curriculum renewal in every teaching cycle where the specific content in the curriculum can be negotiated among students, academics and external collaborators. This type of on-going negotiation becomes part of normal curriculum activities.

There are examples of re-building strategies. The obvious examples are the reform universities that were established during the 60s and 70s, of which several have demonstrated that more student centred learning systems, combined with new types of academic values, are possible. McMaster, Maastricht, Roskilde and Aalborg universities and, more recently, Olin College serve as living laboratories for student centred learning. Olin College was established with a student-centred pedagogy from the very beginning. Students are working with real problems and are involved in designing new innovations within traditional discipline classes as well as across disciplines.

Another example is to build up parallel programs to the existing programs. One example is a Swedish case within computer science that was established as a program with the aim to attract women to computer science (Dahlgren 2002; Salminen-Karlsson 2002). The curriculum in this program was organized as problem and project based learning. The disadvantage with this parallel program strategy is often that at a certain time, resources are lacking and low student recruitment may force merging courses across the two internally competing programs; very few parallel programs have survived. Nevertheless, this can be a useful way of proving that an alternative approach can be successful, e.g. in attracting more women into STEM disciplines.

There are examples of programs or institutions that have gone through a re-building process, but not in relation to sustainability, but to the employability agenda. These rebuilding exercises will need a systems approach by rethinking learning outcomes together with how disciplines, process and generic skills interact with each other in new ways (Dowling and Hadgraft 2013).

An example of a re-building process is Iron Range Engineering, a unique complete PBL curriculum (Ulseth and Johnson 2014). They have changed the philosophy of teaching and learning by going for a rather comprehensive change in the entire curriculum with a focus on educating graduates with integrated academic knowledge and process and generic skills. The curriculum is organized around projects-although mostly in the context of industry projects by "solving complex and ill-structured industry problems in mining, milling, and manufacturing industries".

Here, reflections and feedback are built into the students' learning loops and the role of the academics have changed from presenting content and assessing how well students perform to facilitating the students' learning. The curriculum in this case is regarded as a learning process where students have to identify problems and devise possible technical solutions to these problems while explicitly developing employability skills.

This example does not reflect the sustainability aspect or the societal aspect. However, this could easily be integrated as it is a question of which kind of requirements that students will identify (Ulseth and Johnson 2014). 
No matter which type of re-building strategy one applies, the creation of or re-building will need involvement at the system level. The leader interventions will be quite different compared to the add-on and the integration strategies as it will involve change of both the discipline boundaries, the teaching and learning and by that the approach to what learning is about. Visions, shared experiences, organisational trust, infrastructures, resources and, not least faculty development, will be necessary elements in such a strategy.

Top-down leader intervention will be needed in such processes, as there will be resistance among faculty; however, bottom up action will also be needed; otherwise there will be no community progress in the desired directions. A re-building strategy cannot be applied quickly - it has to be planned months or years ahead by educating change agents who are able to act as knowledge catalysts and coordinators at the system level.

For faculty development, the advantages with such a strategy are that the new aligned system will involve the entire system; however the disadvantage will be that not all academic faculty will join such an effort if this is a change of existing curriculum practice. There will be a certain percentage of academic faculty that will leave and it might be a tumultuous period.

\section{Discussion and perspectives}

The three strategies presented have been described as independent typologies with their own logic; however, there will be overlaps and concrete actions that might belong to both an add-on strategy and an integration strategy. Of course, one strategy can inform the next: individual academics might begin with an add-on strategy, move to an integration strategy over time and then be able to push for a rebuilding strategy with the right institutional support.

The goals of the three strategies are quite diverse. The add-on strategy responds to current requirements, and it preserves the existing system and leaves the academic disciplines and cultures largely untouched. The integration strategy often responds to an employability agenda, encouraged by companies and industrial organisations that want graduates to learn process and professional skills in relation to industrial contexts; however, mostly the academic discipline boundaries remain untouched; new project courses carry the integration.

The re-building strategy is an overall response to both industrial and societal/political agendas that focus on the education of academics as change agents with a deeper awareness of the impact of new innovation on different organisations and actors. The rebuilding strategy requires that disciplinary borders must be negotiated, as it requires both bigger units and involvement of practice.

No matter which strategy that institutions apply, it will involve systemic thinking, including leader interventions and faculty development activities. The add-on strategy is often regarded as a non-systemic strategy as it basically preserves the current system; however, it is still a systemic choice whether there is a change of current curriculum practice or it is a continuation of the existing curriculum practice with some extra opportunities linked into the core of the curriculum.

The role of the leader and faculty development strategies will also differ according to which goal the institution is pursuing. The add-on strategy requires daily operations to maintain the system, respond to external requirements and, by faculty training, optimize the teaching and learning within the classroom. 
The integration strategy requires coordination and collaboration at the system level involving both top-down and bottom up processes. The faculty development unit has a serious role in training groups of teachers and especially to overcome barriers between disciplines and skills training. As skills training will be integrated into the various courses, it will involve new teaching and learning methods like more active learning and problem based and project based learning on a course level.

The re-building strategy will require even more as it will involve negotiation of the existing discipline and course boundaries to create bigger units for more complex learning involving both academic theory, contextual problem analysis, contextual problem solving and awareness of possible societal impacts. The goal of the re-building strategy is at an emerging stage, and it is not a dominant trend at the moment.

For a systemic change, all three strategies can be applied-and at one institution, all three strategies might be applied at different stages in the change process or at different departments. The call for systemic change that has been formulated by several stakeholders will require institutions to develop more systemic curriculum responses. From a sustainability perspective, Steven Sterling has clearly formulated different levels of systemic change-from accepting new subjects added to the discipline, to commit to new values and objectives for the education and last but not least, and at the most complex stage of systemic change, to change the epistemological base and core identity of the educational carriers. In this article we have tried to make a first attempt to formulate more coherent institutional response strategies for institutions to reflect and develop current strategies.

Open Access This article is distributed under the terms of the Creative Commons Attribution 4.0 International License (http://creativecommons.org/licenses/by/4.0/), which permits unrestricted use, distribution, and reproduction in any medium, provided you give appropriate credit to the original author(s) and the source, provide a link to the Creative Commons license, and indicate if changes were made.

\section{References}

Baillie, C., Reader, J., \& Kabo, J. (2012). Heterotopia: Alternative pathways to social justice. Alresford: John Hunt Publishing.

Barnett, R. (2010). Being a University (1st ed.). New York: Routledge.

Barnett, R., Parry, G., \& Coate, K. (2001). Conceptualising curriculum change. Teaching in Higher Education, 6(4), 435-449. doi:10.1080/13562510120078009.

Barrows, H. S., \& Tamblyn, R. M. (1980). Problem-based learning: An approach to medical education. Berlin: Springer.

Besterfield-Sacre, M., Cox, M. F., Borrego, M., Beddoes, K., \& Zhu, J. (2014). Changing engineering education: Views of US faculty, chairs, and deans. Journal of Engineering Education, 103(2), 193-219. doi:10.1002/jee.20043.

Bologna Working Group. (2005). A framework for qualifications of the European higher education area. Bologna working group report on qualifications frameworks. Copenhagen DK: Ministry of Science, Technology and Innovation.

Boyce, M. E. (2003). Organizational learning is essential to achieving and sustaining change in higher education. Innovative Higher Education, 28(2), 119-136. doi:10.1023/B:IHIE.0000006287.69207.00.

Broadbent, J., Laughlin, R., \& Alwani-Starr, G. (2010). Steering for sustainability. Public Management Review, 12(4), 461-473. doi:10.1080/14719037.2010.496257.

Brulin, G., \& Svensson, L. (2012). Managing sustainable development programmes. London: Gower.

Cameron, I., \& Hadgraft, R. (2010). Engineering and ICT learning and teaching academic standards statement. Sydney: Australian Learning and Teaching Council. http://disciplinestandards.pbworks. com/w/page/52657697/FrontPage

CDIO. (2014a). CDIO history. http://www.cdio.org/cdio-history. Accessed 13 August 2014.

CDIO. (2014b). CDIO vision. http://www.cdio.org/cdio-vision. Accessed 13 August 2014. 
Clark, B. R., Pergamon, B. R., \& Clark, B. C. (2001). Creating entrepreneurial universities: organizational pathways of transformation. Oxford; New York: Emerald Group Publishing Limited.

Cotton, D. R., \& Alcock, I. (2012). Commitment to environmental sustainability in the UK student population. Studies in Higher Education, 38(10), 1457-1471. doi:10.1080/03075079.2011.627423.

Crawley, E. F., Malmqvist, J., Östlund, S., Brodeur, D. R., \& Edström, K. (2014). The CDIO approach. In Rethinking engineering education (pp. 11-45). Berlin: Springer. http://link.springer.com/chapter/10. 1007/978-3-319-05561-9_2. Accessed 28 September 2014.

Crosthwaite, J. L., \& Kavanagh, L. (2010). An evaluation of the EWB challenge-implications for future curriculum change. In Proceedings of the 2010 Australasian association for engineering education conference. Sydney.

Dahlgren, M. A. (2002). Portraits of PBL: A cross-faculty comparison of students' experiences of problembased learning. Linköping: Linköpings universitet, Department of Behavioural Sciences.

de Graaff, E., \& Kolmos, A. (2006). Management of change. Rotterdam: Sense Publishers.

Debowski, S. (2014). From agents of change to partners in arms: The emerging academic developer role. International Journal for Academic Development, 19(1), 50-56. doi:10.1080/1360144X.2013.862621.

Dowling, D. G., \& Hadgraft, R. (2013). The DYD stakeholder consultation process-A user guide. http:// www.olt.gov.au/resource-DYD-defining-your-discipline. Accessed 13 August 2014.

Drew, G. (2010). Issues and challenges in higher education leadership: Engaging for change. The Australian Educational Researcher, 37(3), 57-76. doi:10.1007/BF03216930.

Edström, K., \& Kolmos, A. (2014). PBL and CDIO: Complementary models for engineering education development. European Journal of Engineering Education, 39(5), 539-555. doi:10.1080/03043797. 2014.895703 .

Engineers Australia. (2011). Stage 1 competency standard for professional engineer. http://www.engineers australia.org.au/sites/default/files/shado/Education/ProgramAccreditation/110318Stage1Professional Engineer.pdf. Accessed 7 January 2012.

Engineers Without Borders. (2014). EWB Challenge. http://www.ewbchallenge.org.

European Commission. (2009). Communiqué of the conference of European ministers responsible for higher education, Leuven and Louvain-la-Neuve, 28-29 April 2009. http://europa.eu/rapid/press-release_IP09-675_en.htm. Accessed 6 February 2015.

Fadeeva, Z., Mochizuki, Y., Hopkinson, P., \& James, P. (2010). Practical pedagogy for embedding ESD in science, technology, engineering and mathematics curricula. International Journal of Sustainability in Higher Education, 11(4), 365-379. doi:10.1108/14676371011077586.

Felletti, G., \& Boud, D. (1997). The challenge of problem based learning. London: Taylor \& Francis. http:// www.saxo.com/dk/the-challenge-of-problem-based-learning_david-boud_hardback_9780749422912. Accessed 15 October 2014.

Fullan, M. (2007a). The new meaning of educational change (4th ed.). New York: Teachers College Press. Fullan, M. (2007b). Leading in a culture of change. San Francisco: Jossey-Bass (Revised edition).

Gibbs, G. (2013). Reflections on the changing nature of educational development. International Journal for Academic Development, 18(1), 4-14. doi:10.1080/1360144X.2013.751691.

Goldberg, D. E., \& Sommerville, M. (2014). A whole new engineer (1st ed.). Douglas, MI: ThreeJoy Associates Inc.

Graham, R. (2010). UK approaches to engineering project-based learning white paper sponsored by the Bernard M. Gordon-MIT engineering leadership program. Bernard M. Gordon MIT engineering leadership program.

Graham, R. (2012). Achieving excellence in engineering education: The ingredients of successful change. The Royal Academy of Engineering. www.raeng.org.uk

Haase, S. (2013a). Engineering students' sustainability approaches. European Journal of Engineering Education, 39(3), 247-271. doi:10.1080/03043797.2013.858103.

Haase, S. (2013b). An engineering dilemma: Sustainability in the eyes of future technology professionals. Science and Engineering Ethics, 19(3), 893-911. doi:10.1007/s11948-012-9417-0.

Hadgraft, R., \& Muir, P. (2003). Defining graduate capabilities for chemical engineers at RMIT. In Proceedings of AaeE conference 29 September to 1 October 2003 (pp. 91-102). Austral Asian Association for Engineering Education.

Hadgraft, R., Xie, M., \& Angeles, N. (2004). Civil and infrastructure engineering for sustainability. Salt Lake City: Presented at the ASEE annual conference.

Hannah, S. T., \& Lester, P. B. (2009). A multilevel approach to building and leading learning organizations. The Leadership Quarterly, 20(1), 34-48. doi:10.1016/j.leaqua.2008.11.003.

Henderson, C., Beach, A., \& Finkelstein, N. (2011). Facilitating change in undergraduate STEM instructional practices: An analytic review of the literature. Journal of Research in Science Teaching, 48(8), 952-984. doi:10.1002/tea.20439. 
Holgaard, J. E., de Graaff, E., \& Kolmos, A. (2010). Sustainability in the practice, mindset and heart of engineering. Presented at the ESRSCP-EMSU Conference. http://vbn.aau.dk/da/publications/ sustainability-in-the-practise-mindset-and-heart-of-engineering(73d7bba8-f7b5-43ac-948b-49223159 267a).html. Accessed 15 October 2014.

Holmberg, J., Lundqvist, U., Svanström, M., \& Arehag, M. (2012). The university and transformation towards sustainability: The strategy used at Chalmers University of Technology. International Journal of Sustainability in Higher Education, 13(3), 219-231. doi:10.1108/14676371211242544.

International Engineering Alliance. (2013). Graduate attributes and professional competencies. http://www. ieagreements.org/IEA-Grad-Attr-Prof-Competencies.pdf.

International Engineering Alliance. (2015). Washington Accord. http://www.ieagreements.org/washingtonaccord/.

Jamison, A., Christensen, S. H., \& Botin, L. (2011). A Hybrid imagination: Science and technology in cultural perspective. Synthesis Lectures on Engineers, Technology and Society, 6(2), 1-180. doi:10. 2200/S00339ED1V01Y201104ETS016.

Jamison, A., Kolmos, A., \& Holgaard, J. E. (2014). Hybrid learning: An integrative approach to engineering education. Journal of Engineering Education, 103(2), 253-273. doi:10.1002/jee.20041.

Johnston, L. F. (2013). Higher education for sustainability: Cases, challenges, and opportunities from across the curriculum. New York: Routledge. https://www.dawsonera.com/guard/protected/dawson. jsp?name=https://idp.worc.ac.uk/oala/metadata\&dest=http://www.dawsonera.com/depp/reader/protected/ external/AbstractView/S9780203123041. Accessed 16 October 2014.

Jones, P., Selby, D., \& Sterling, S. (2010). Sustainability education-Perspectives and practice across higher education. New York: Earthscan.

King, R. (2008). Addressing the supply and quality of engineering graduates for the new century. http:// www.olt.gov.au/resource-addressing-supply-quality-engineering-graduates-uts-2008. Accessed 27 November 2014.

Knight, P. T. (2001). Complexity and curriculum: A process approach to curriculum-making. Teaching in Higher Education, 6(3), 369-381. doi:10.1080/13562510120061223.

Knoster, T., Villa R, \& Thousand J. (2000). A framework for thinking about systems change. In R. Villa \& J. Thousand (Eds.), Restructuring for caring and effective education: Piecing the puzzle together. Baltimore: Paul H. Brookes Publishing Co.

Kolmos, A., \& Graaff, E. D. (2014). Problem-based and project-based learning in engineering education. In B. M. Olds \& A. Johri (Eds.), Cambridge handbook of engineering education research (pp. 141-161). Cambridge: Cambridge University Press.

Kotter, J. P. (1995). Leading change: Why transformation efforts fail. Harvard Business Review, 73(2), 59-67.

Louvel, S. (2013). Understanding change in higher education as bricolage: How academics engage in curriculum change. Higher Education, 66(6), 669-691. doi:10.1007/s10734-013-9628-6.

Magnell, M., Geschwind, L. A., Gumaelius, L. B., \& Kolmos, A. (2014). Faculty approaches to working life issues in engineering curricula. Presented at the 121st ASEE annual conference and exposition. http:// vbn.aau.dk/da/publications/faculty-approaches-to-working-life-issues-in-engineering-curricula(12ebc2 4b-3994-4387-9dc4-ae7b25dd1abf)/export.html. Accessed 16 October 2014.

Marshall, S. (Ed.). (2007). Strategic leadership of change in higher education: What's new? New York: Routledge.

McKenna, A. F., Froyd, J., \& Litzinger, T. (2014). The Complexities of transforming engineering higher education: Preparing for next steps. Journal of Engineering Education, 103(2), 188-192. doi:10.1002/ jee.20039.

National Academy of Engineering. (2004). The engineer of 2020: Visions of engineering in the new century. Accessed 25 November 2014. http://www.nap.edu/catalog/10999/the-engineer-of-2020-visions-ofengineering-in-the-new.

Reidsema, C., Hadgraft, R., Cameron, I., \& King, R. (2013). Change strategies for educational transformation. http://search.informit.com.au/documentSummary; dn=810983996591111;res=IELENG. Accessed 16 October 2014

RMIT. (2014). Engineering, society and sustainability. http://www.rmit.edu.au/courses/035198. Accessed 13 August 2014.

Royal Academy of Engineering. (2007). Educating engineers for the 21st century. The Royal Academy of Engineering. http://www.raeng.org.uk/publications/reports?p=6. Accessed 27 November 2014.

Salminen-Karlsson, M. (2002). Gender-inclusive computer engineering education: Two attempts at curriculum change. International Journal of Engineering Education, 18(4), 430-437. Accessed 25 May 2015.

Savin-Baden, M. (2003). Facilitating problem-based learning (1st ed.). Maidenhead: Open University Press. 
Schierenbeck, C. (2013). Adaptive change in higher education. In Fixing higher education (pp. 153-162). Springer Fachmedien Wiesbaden. http://link.springer.com/chapter/10.1007/978-3-658-00213-8_12. Accessed 15 October 2014.

Seidel, J., Hadgraft, R. G., \& Eley, M. (1994). Student contractors bid for soils engineering jobs. Presented at the 6th Australasian Association for Engineering Education Conference, Sydney.

Shephard, K., \& Furnari, M. (2012). Exploring what university teachers think about education for sustainability. Studies in Higher Education, 38(10), 1577-1590. doi:10.1080/03075079.2011.644784.

Sheppard, S. D., Pellegrino, J. W., \& Olds, B. M. (2008). On becoming a 21 st century engineer. Journal of Engineering Education, 97(3), 231-234. doi:10.1002/j.2168-9830.2008.tb00972.x.

Spinks, N., Silburn, N., \& Birchall, D. (2006). Educating engineers for the 21st century: The industry view. The Royal Academy of Engineering. http://www.raeng.org.uk/publications/reports?p=7\#sthash. 0yS6yhdX.dpuf

Sterling, S. (2001). Sustainable education: Re-visioning learning and change. Schumacher Briefings. Schumacher UK, CREATE Environment Centre, Seaton Road, Bristol, BS1 6XN, England (6 pounds). E-mail: admin@schumacher.org.uk; Web site: http://www.schumacher.org.uk. http://eric.ed.gov/?id= ED464791. Accessed 21 August 2014.

The Franklin W. Olin College of Engineering. (2015). http://www.olin.edu.

Tryggvason, G., \& Apelian, D. (2011). Shaping our world: Engineering education for the 21st century. New York: Wiley.

Ulseth, R., \& Johnson, B. (2014). PBL curriculum-startup phase complete. In Frontiers in education. Presented at the frontiers in education conference, Madrid 22-26 October.

United Nations. (2014). UN decade of education for sustainable development-Strong sustainability. http:// nz.phase2.org/partnerships/unesco/un-decade-of-education-for-sustainable-development. Accessed 27 November 2014.

Wals, A. E. J. (2007). Social learning towards a sustainable world (Vol. 2007). Wageningen: Wagening Academic Publisers.

Wals, A. E. J., \& Corcoran, P. B. (2012). Learning for Sustainability—In times for accellerating change. Wageningen: Wagening Academic Publisers. 